\title{
SINTESIS 3-(3,4-DIMETOKSI FENIL)-1-PROPANOL MELALUI HIDROBORASI METILEUGENOL MENGGUNAKAN $\mathrm{H}_{3} B$ :DIETILETER
}

\author{
Ngadiwiyana, Ismiyarto dan M. Fathoni \\ Laboratorium Kimia Organik \\ Jurusan Kimia Fakultas Matematika dan Ilmu Pengetahuan Alam \\ Universitas Diponegoro, Semarang
}

\begin{abstract}
ABSTRAK
Penelitian ini merupakan usaha untuk meningkatkan nilai guna dari minyak daun cengkeh dengan memanfaatkan kandungan utamanya yaitu eugenol. Eugenol dapat diubah menjadi metileugenol lalu dikonversi menjadi 3-(3,4-dimetoksi fenil)-1-propanol melalui reaksi hidroborasi dengan menggunakan reagen $\mathrm{H}_{3} B$ :dietileter. Kemudian, dioksidasi menggunakan hidrogen peroksida yang diikuti dengan hidrolisis dalam suasana basa untuk memperoleh alkohol. Produk sintesis dianalisis menggunakan spektrometer FTIR dan GC-MS. Data spektra FTIR memperlihatkan serapan kuat oleh gugus hidroksil pada bilangan gelombang 3448,5 $\mathrm{cm}^{-1}$. Hal ini menunjukkan bahwa senyawa 3-(3,4dimetoksifenil)-1-propanol telah terbentuk. Hasil ini diperkuat oleh pola fragmentasi senyawa pada data $M S$ yang menunjukkan adanya puncak dasar dengan $\mathrm{m} / \mathrm{z}=151$ dan ion molekul dengan $\mathrm{m} / \mathrm{z}=196$ yang merupakan berat molekul dari senyawa 3-(3,4-dimetoksi fenil)-1-propanol. Produk sintesis yang diperoleh memiliki rendemen mencapai $81,29 \%$. Selanjutnya, senyawa ini digunakan sebagai senyawa antara dalam sintesis turunan antibiotik C-9154.
\end{abstract}

Kata Kunci: Metileugenol, Hidroborasi, Borana.

\section{SYNTHESIS OF 3-(3,4-DIMETHOXY PHENYL)-1-PROPANOL THROUGH HY- DROBORATION OF METHYLEUGENOL USING H3B:DIETHYLETHER}

\begin{abstract}
This research represent to increase the utilize of clove oil by exploiting a most compound is eugenol. Eugenol can be turned into metileugenol so it can converted to 3-(3,4-dimethoxy phenyl)-1propanol through hydroboration reaction of methyleugenol using a borane-dietileter solution. Then, it was oxidized by hydrogen peroxide followed with hydrolysis in base solution to produce an alcohol. The product of synthesis was analyzed by spectrometer FTIR and GC-MS. Data IR showed strong absorption with bunch of hydroxyl at wave number 3448,5 $\mathrm{cm}^{-1}$ that indicated the compound 3-(3,4-dimethoxy phenyl)-1-propanol had been produced with strenghtened by MS data. MS data showed the fragmentation pattern of product with base peak at $\mathrm{m} / \mathrm{z}=151$ and molecule ion at $\mathrm{m} / \mathrm{z}=196$ representing molecule weight from compound 3-(3,4-dimethoxy phenyl)-1-propanol. Product synthesis obtained by rendemen up to $81,29 \%$. This compound used as intermediet in synthesis of antibiotic C-9154 derivative.
\end{abstract}

Key word: Methyleugenol, Hydroboration, Borane.

\section{PENDAHULUHAN}

Penggunaan minyak daun cengkeh di negara Indonesia masih sangat terbatas. Dalam bidang industri, penggunaan minyak daun cengkeh masih terbatas pada industri parfum, penyedap rasa pada makanan dan sebagian besar diekspor dalam bentuk minyak mentah, sehingga kurang memberikan sumbangan devisa negara karena harganya relatif murah (Anwar,1994). Oleh karena itu, diperlukan usaha untuk meningkatkan nilai guna dari minyak daun cengkeh, salah satunya dengan memanfaatkan kandungan utama minyak daun cengkeh. Kandungan utama minyak daun cengkeh adalah senyawa fenolik yang dikenal dengan nama eugenol dengan kandungan sekitar 80-90\% dan kariofilena.

Telah banyak dilakukan penelitian untuk membuat turunan eugenol melalui konversi gugus hidroksil menjadi metileugenol. Metileugenol sudah mulai populer digunakan sebagai pengendali hama yang relatif aman dan ekonomis di beberapa negara, termasuk Indonesia. 


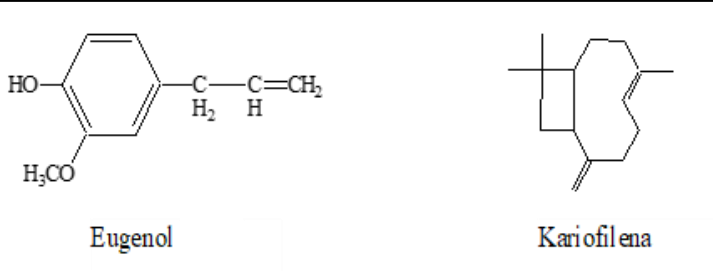

Metileugenol dapat disintesis melalui reaksi metilasi eugenol menggunakan dimetil sulfat dalam media basa. Anwar (1994) telah berhasil mensintesis metileugenol dengan rendemen sebesar $90,5 \%$.

Dalam penelitian ini, dilakukan sintesis senyawa 3-(3,4-dimetoksi fenil)-1-propanol dari metileugenol melalui reaksi hidroborasi. Kemudian, produk sintesis tersebut akan digunakan sebagai senyawa antara dalam sintesis turunan antibiotik C-9154. Secara keseluruhan reaksi hidroborasi merupakan reaksi adisi elektrofilik yang menghasilkan produk Anti-Markovnikov dan Syn Adisi (Carey, 2003). Reagen yang digunakan dalam reaksi hidroborasi adalah borana $\left(\mathrm{BH}_{3}\right)$. Borana yang sering digunakan telah tersedia diperdagangan yaitu $\mathrm{BH}_{3}$ dalam pelarut THF $\left(\mathrm{H}_{3} \mathrm{~B}: \mathrm{THF}\right)$ namun pengembangan metode dengan berbagai tinjauan baik dari segi ekonomi, keamanan, kemudahan dalam penggunaan maupun tinjauan reagen dengan selektivitas yang tinggi masih menjadi pokok bahasan yang sangat penting dalam penelitian reaksi hidroborasi.

Dalam penelitian ini akan dikembangkan suatu metode sintesis melalui reaksi hidroborasi menggunakan $\mathrm{BH}_{3}$ dalam pelarut dietileter $\left(\mathrm{H}_{3} \mathrm{~B}\right.$ :dietileter). Secara skematis, sintesis 3-(3,4dimetoksi fenil)-1-propanol dari eugenol sebagai berikut:
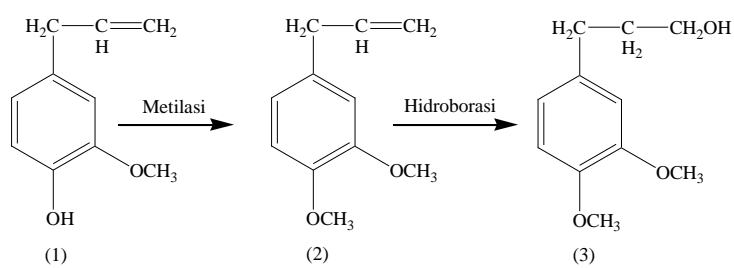

Berdasarkan penelitian terdahulu diperoleh data bahwa reaksi hidroborasi menggunakan $\mathrm{H}_{3} \mathrm{~B}$ :THF menghasilkan rendemen $80 \%$ (Siadi, 2001). Penggunaan reagen $\mathrm{BH}_{3}$ dalam pelarut dietileter $\left(\mathrm{H}_{3} \mathrm{~B}\right.$ :dietileter $)$ pada reaksi hidroborasi metileugenol merupakan pengembangan metode sintesis dengan pelarut yang lebih murah dan mudah dalam penanganan. Hal ini diharapkan dapat menghasilkan produk Anti Markovnikov yaitu senyawa 3-(3,4-dimetoksi fenil)-1-propanol sehingga dapat digunakan sebagai reagen dalam suatu reaksi hidroborasi selain reagen $\mathrm{H}_{3} \mathrm{~B}$ :THF.

\section{TUJUAN PENELITIAN}

Secara umum penelitian ini bertujuan untuk mengubah eugenol menjadi senyawa lain yang lebih berguna yaitu turunan antibiotik C-9154 sehingga diharapkan dapat memberikan sumbangan bagi peningkatan devisa negara dan juga perkembangan ilmu kimia, khususnya bidang kimia organik sintetik. Tujuan khusus dari penelitian ini adalah sintesis senyawa 3-(3,4-dimetoksifenil)-1-propanol melalui hidroborasi metileugenol menggunakan $\mathrm{H}_{3} \mathrm{~B}$ :dietileter.

\section{METODA PENELITIAN}

Sintesis 3-(3,4-dimetoksi fenil)-1-propanol dilakukan melalui reaksi hidroborasi metileugenol menggunakan $\mathrm{H}_{3} \mathrm{~B}$ :dietileter pada suhu $0^{\circ} \mathrm{C}$ dan kondisi inert untuk menghasilkan trialkilborana. Kemudian, trialkilborana dioksidasi menggunakan hidrogen peroksida $30 \%$ yang diikuti dengan hidrolisis dalam suasana basa untuk memperoleh alkohol. Produk sintesis di ekstraksi menggunakan eter dan dievaporasi kemudian dianalisis menggunakan spektrometer FTIR dan GC-MS.

Alat. Alat-alat yang digunakan dalam penelitian ini antara lain, peralatan gelas, satu set alat tabung gas nitrogen, labu leher tiga yang dilengkapi dengan pengaduk magnet, corong penetes, termometer, dan pendingin bola yang telah dipasang tabung silika, neraca analitis, set alat ekstraksi, pengukur $\mathrm{pH}$, rotary evaporator, Spektrofotometer FTIR dan GC-MS merk Shimadzu QP-5000.

Bahan. Bahan-bahan yang digunakan adalah metileugenol yang telah tersedia diperdagangan, natrium borohidrida berbentuk padatan putih yang disimpan pada suhu rendah, boron trifluorida-dietileterat yang diperoleh diperdagangan, 
akuades, natrium hidroksida $3 \mathrm{M}$, hidrogen peroksida $30 \%$, natrium sulfat dan pelarut dietileter pa.

Cara Kerja. Penelitian dilakukan di Laboratorium Kimia Organik FMIPA Universitas Diponegoro Semarang. Analisa hasil dilakukan di Laboratorium Kimia Organik Universitas Gadjah Mada Yogyakarta. Sintesis 3-(3,4-dimetoksi fenil)-1-propanol: ke dalam labu leher tiga ukuran $250 \mathrm{~mL}$ yang telah dilengkapi dengan pengaduk magnet, corong penetes, termometer, pendingin bola dan tabung berisi silika serta pendingin es, dimasukkan $100 \mathrm{~mL}$ dietileter dan natrium borohidrida 3,0264 g sambil diaduk pada suhu $0^{\circ} \mathrm{C}$. Ditambahkan larutan boron trifluorida dietileterat sebanyak $20,09 \mathrm{~mL}$ secara perlahan-lahan melalui corong penetes selama 20 menit kemudian ditambahkan metileugenol sebanyak 16,51 mL dan diaduk selama 30 menit. Pendingin es diambil sambil terus diaduk selama 60 jam pada suhu kamar. Ditambahkan akuades untuk menghilangkan natrium borohidrida yang berlebih. Kemudian, ditambahkan larutan natrium hidroksida $3 \mathrm{M}$ sebanyak $50 \mathrm{~mL}$ dan $21,93 \mathrm{~mL}$ hidrogen peroksida $30 \%$ sambil terus diaduk selama 4 jam pada suhu $45^{\circ} \mathrm{C}$.

Campuran hasil reaksi diektraksi dua kali dengan $25 \mathrm{~mL}$ dietil eter dan lapisan organik dipisahkan dari campurannya, kemudian dikeringkan dengan natrium sulfat anhidrat dan selanjutnya dievaporasi. Hasil reaksi dihitung rendemendandianalisis dengan spektrofotometer FTIR dan GC-MS.

\section{HASIL PEMBAHASAN}

Sintesis 3-(3,4-dimetoksi fenil)-1-propanol.

Sintesis 3-(3,4-dimetoksi fenil)-1-propanol dilakukan melalui reaksi hidroborasi metileugenol. Reagen yang digunakan dalam reaksi hidroborasi adalah borana $\left(\mathrm{BH}_{3}\right)$. Pada prinsipnya reaksi hidroborasi merupakan metode untuk mengkonversi gugus alkena menjadi gugus alkohol. Senyawa alkena akan bereaksi dengan $\mathrm{BH}_{3}$ membentuk trialkilborana kemudian langsung dioksidasi dengan hidrogen peroksida yang diikuti dengan hidrolisis dalam suasana basa untuk menghasilkan senyawa alkohol.

Langkah awal dalam penelitian ini adalah melakukan sintesis reagen $\mathrm{H}_{3} \mathrm{~B}$ :dietileter secara in situ dengan mereaksikan $\mathrm{NaBH}_{4}$ dan $\mathrm{BF}_{3}$ :dietileterat pada suhu $0^{\circ} \mathrm{C}$ dan kondisi inert yang dibuat dengan mengalirkan gas nitrogen ke dalam sistem, dimana reaksi yang terjadi adalah:

$3 \mathrm{NaBH}_{4}+4 \mathrm{BF}_{3} \longrightarrow 2 \mathrm{~B}_{2} \mathrm{H}_{6}+3 \mathrm{NaBF}_{4}$

Gas diborana $\left(\mathrm{B}_{2} \mathrm{H}_{6}\right)$ tersebut akan terdisosiasi menjadi monomernya $\left(\mathrm{BH}_{3}\right)$ dalam pelarut eter, dimana borana yang terbentuk akan terstabilkan oleh atom oksigen dalam sistem eter.

$\mathrm{B}_{2} \mathrm{H}_{6}+2 \mathrm{O}\left(\mathrm{C}_{2} \mathrm{H}_{5}\right)_{2} \longrightarrow 2 \mathrm{BH}_{3}: \mathrm{O}\left(\mathrm{C}_{2} \mathrm{H}_{5}\right)_{2}$ Apabila ditinjau dari struktur lewis maka didapatkan:

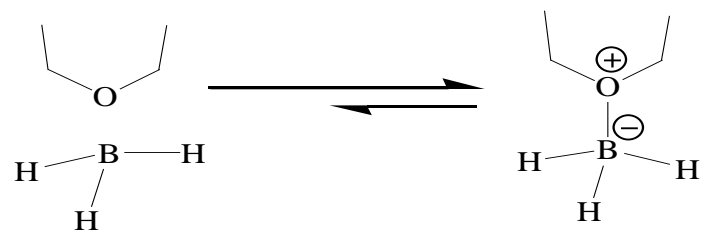

Setelah itu ditambahkan metileugenol dan diaduk selama 60 jam pada suhu kamar. Pada penelitian ini, dicoba pengadukan selama 6 jam kemudian dari spektra FTIR yang dihasilkan menunjukkan terjadinya konversi gugus alkena pada metileugenol menjadi gugus alkohol yang kurang maksimal. Hal ini dapat dilihat pada serapan yang lemah oleh gugus hidroksil yang terjadi pada bilangan gelombang $3452,3 \mathrm{~cm}^{-1}$ sebagaimana yang tercantum pada lampiran 4 . Pada prinsipnya reaksi yang terjadi merupakan reaksi adisi elektrofilik. Elektron $\pi$ pada ikatan rangkap dalam metileugenol akan bertindak sebagai nukleofil yang akan menyerang atom boron (B) sebagai elektrofilnya. Pada saat borana $\left(\mathrm{BH}_{3}\right)$ mengadisi suatu ikatan rangkap, atom boron dan ion hidrida akan terikat pada kedua atom karbon dari ikatan rangkap secara serempak. Hasilnya adalah bahwa B dan $\mathrm{H}$ harus ditambahkan dari satu sisi yang sama dari ikatan rangkap itu sehingga secara stereokimia reaksi ini merupakan reaksi syn adisi (Fessenden, 
1997). Secara stereokimia dapat digambarkan sebagai berikut:

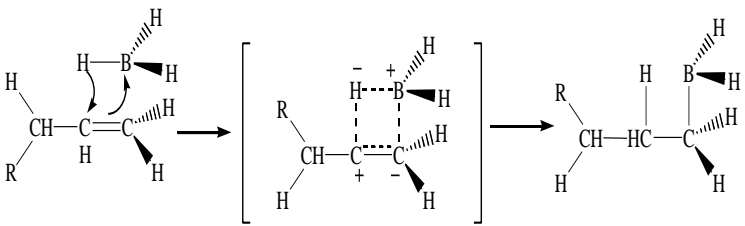

Ditinjau dari regioselektifitasnya, reaksi hidroborasi menghasilkan produk adisi anti-Markovnikov. Atom hidrogen akan menyerang atom karbon yang lebih tersubstitusi dan atom boron terikat pada atom karbon yang kurang tersubstitusi.

Borana $\left(\mathrm{BH}_{3}\right)$ bereaksi dengan cepat dan kuantitatif dengan metileugenol membentuk organoborana. Reaksi keseluruhan merupakan hasil tiga tahap reaksi yang terpisah. Dalam tiap tahap, satu gugus alkil ditambahkan pada borana sampai ketiga-tiga atom hidrogen digantikan gugus alkil membentuk trialkilborana. Reaksi yang terjadi pada pembentukan trialkilborana sebagai berikut:

Tahap 1. pembentukan monoalkilborana

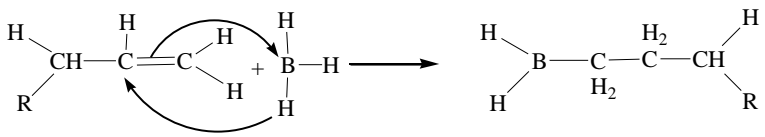

Tahap 2. pembentukan dialkilborana

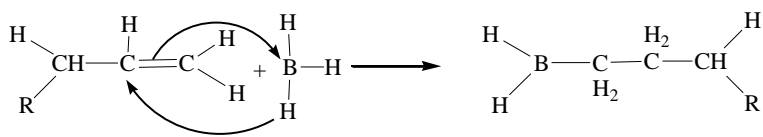

Tahap 3. pembentukan trialkilborana

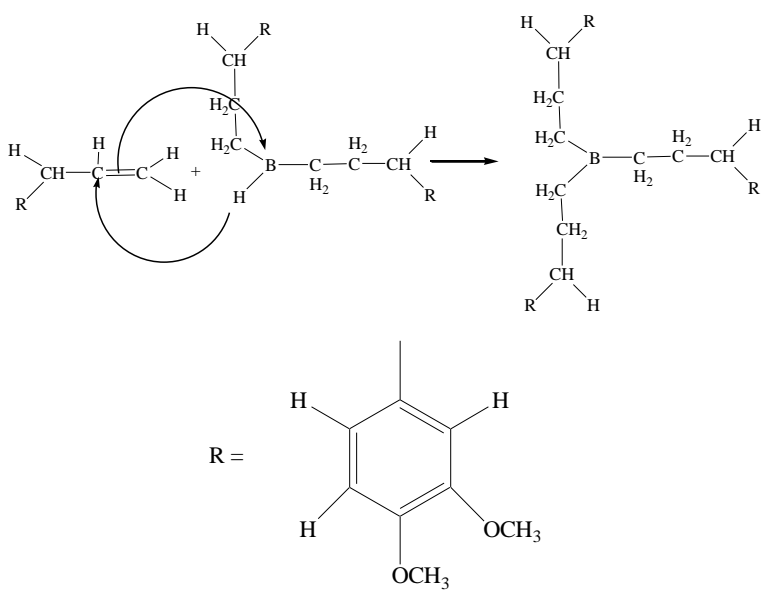

Setelah pengadukan selama 60 jam kemudian dilakukan penambahan air secara perlahan-lahan ke dalam labu reaksi. Hal ini bertujuan untuk menghilangkan natrium borohidrida $\left(\mathrm{NaBH}_{4}\right)$ yang masih tersisa. Larutan natrium borohidrida jika bereaksi dengan air akan terdekomposisi membentuk boraks dan gas hidrogen. Terbentuknya gas hidrogen $\left(\mathrm{H}_{2}\right)$ ditunjukkan dengan terjadinya letupan-letupan gas dalam labu reaksi selama penambahan air. Reaksi yang terjadi seperti di bawah ini:

$$
\mathrm{NaBH}_{4}+2 \mathrm{H}_{2} \mathrm{O} \longrightarrow \mathrm{NaBO}_{2}+4 \mathrm{H}_{2} A
$$

Trialkilborana yang dihasilkan dalam reaksi hidroborasi tanpa diisolasi terlebih dahulu kemudian langsung dioksidasi menggunakan hidrogen peroksida yang diikuti dengan hidrolisis dalam suasana basa, reaksi yang terjadi adalah:

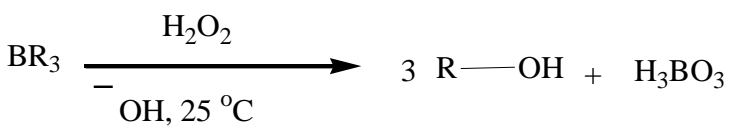

Mekanisme reaksi yang terjadi sebagai berikut:

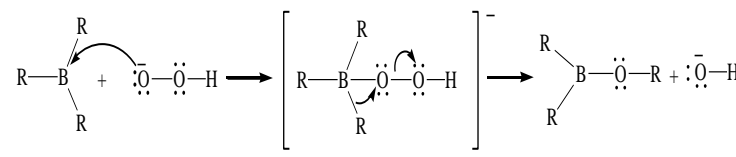

Reaksi tersebut terjadi melalui tiga tahap untuk membentuk trialkil borat. Kemudian trialkil borat tersebut akan terhidrolisis dalam suasana basa menghasilkan tiga molekul senyawa alkohol dan asam borat. Reaksi yang terjadi adalah: $\mathrm{B}(\mathrm{OR})_{3}+3 \mathrm{H}_{2} \mathrm{O} \longrightarrow 3 \mathrm{R}-\mathrm{OH}+\mathrm{H}_{3} \mathrm{BO}_{3}$ Secara keseluruhan sintesis 3-(3,4-dimetoksi fenil)-1-propanol melalui reaksi hidroborasi metileugenol dapat dituliskan sebagai berikut:

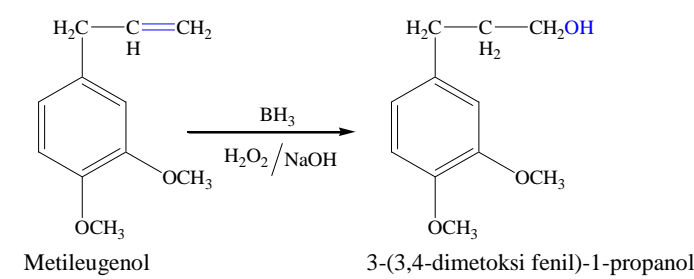

Hasil reaksi hidroborasi-oksidasi metileugenol yang diperoleh kemudian ditentukan rendemennya dan dianalisis dengan spektrofotometer FTIR dan GC-MS. Senyawa hasil reaksi hidroborasi-oksidasi metileugenol berupa cairan kental kekuningan sebesar 15,30 g dan 
memiliki rendemen hasil sebesar 81,29\%. Sehingga reagen $\mathrm{BH}_{3}$ dalam pelarut dietileter dapat digunakan sebagai reagen alternatif dalam reaksi hidroborasi selain reagen $\mathrm{H}_{3} \mathrm{~B}$ :THF yang biasa digunakan.

Hasil analisis produk reaksi hidroborasi-oksidasi metileugenol dengan spektrofotometer FTIR kemudian dibandingkan dengan spektra FTIR metileugenol murni seperti yang tercantum pada gambar 1 di bawah ini:

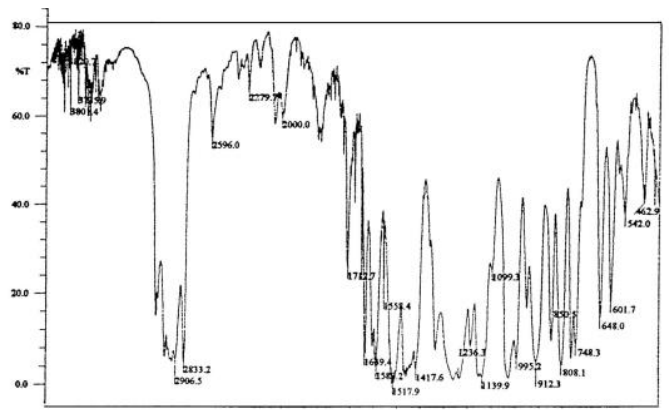

Gambar 1. Spektra FTIR metileugenol murni

Berdasarkan data spektra FTIR senyawa hasil yang diperoleh menunjukkan bahwa telah terjadi konversi gugus alkena pada metileugenol menjadi gugus alkohol seperti tercantum pada gambar 2 sebagai berikut:

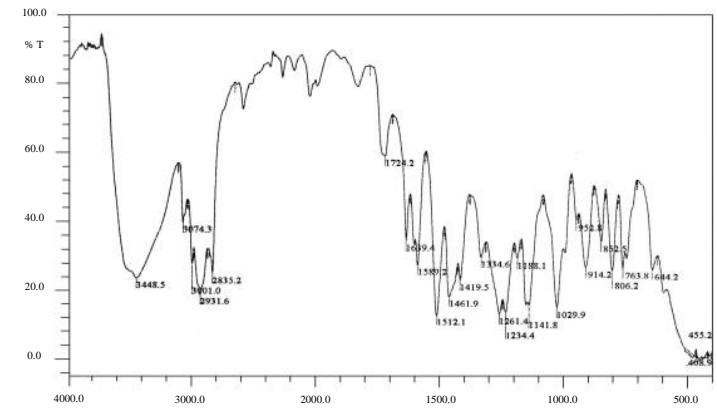

Gambar 2. Spektra FTIR hasil hidroborasioksidasi metileugenol

Data spektra FTIR yang diperoleh memperlihatkan adanya gugus hidroksil yang ditunjukkan oleh serapan kuat pada bilangan gelombang $3448,5 \mathrm{~cm}^{-1}$ yang tidak terdapat pada spektra FTIR metileugenol. Serapan pada bilangan gelombang $3074 \mathrm{~cm}^{-1}$ menunjukkan vibrasi $\mathrm{C}_{\mathrm{sp} 2}-\mathrm{H}$ (aromatik) dan serapan pada bilangan gelombang $1589,2 \mathrm{~cm}^{-1}$ menunjukkan senyawa aromatik yang diperkuat oleh serapan pada bilangan gelombang $806,2 \mathrm{~cm}^{-1}$. Serapan pada bilangan gelombang $2931,6 \mathrm{~cm}^{-1}$ menunjukkan vibrasi
$\mathrm{C}_{\mathrm{sp} 3}-\mathrm{H}$. Serapan pada $1334,6 \mathrm{~cm}^{-1}$ menunjukkan adanya gugus metil dan gugus metilen ditunjukkan pada serapan $763,8 \mathrm{~cm}^{-1}$. Gugus metoksi ($\mathrm{OCH}_{3}$ ) ditunjukkan oleh serapan rentangan C-O yang terjadi pada bilangan gelombang 1234,4 $\mathrm{cm}^{-1}$ dan serapan bilangan gelombang 1029,9 $\mathrm{cm}^{-1}$ disebabkan oleh vibrasi C-O-C.

Berdasarkan data di atas, dapat disimpulkan bahwa senyawa hasil hidroborasi-oksidasi yang dianalisis mengandung gugus hidroksil, gugus metoksi dan cincin aromatis.

Analisis senyawa hasil reaksi hidroborasioksidasi metileugenol dengan GC-MS menunjukkan kromatogram seperti tercantum pada gambar 3 dan spektogram seperti pada gambar 4 .

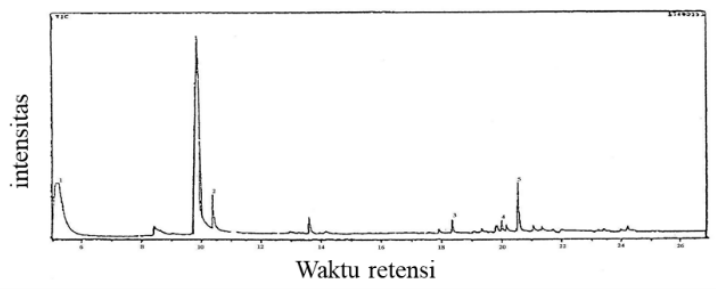

Gambar 3. Kromatogram hasil hidroborasioksidasi metileugenol

Spektogram puncak nomor $1\left(t_{R}=9,95\right.$ menit, 80 $\%)$ menunjukkan puncak ion molekuler pada $\mathrm{m} / \mathrm{z}=196$, yang merupakan berat molekul dari 3-(3,4-dimetoksi fenil)-1-propanol.

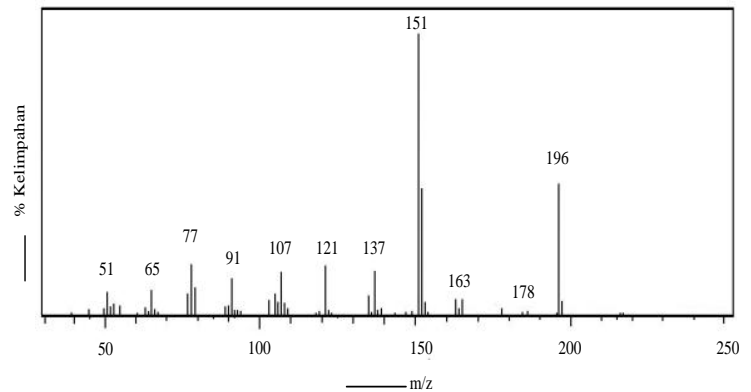

Gambar 4. Spektogram senyawa 3-(3,4-dimetoksi fenil)-1-propanol

Puncak pecahan dengan $\mathrm{m} / \mathrm{z}=151$ sebagai puncak dasar, terbentuk karena strukturnya distabilkan oleh resonansi gugus fenil, seperti digambarkan sebagai berikut: 


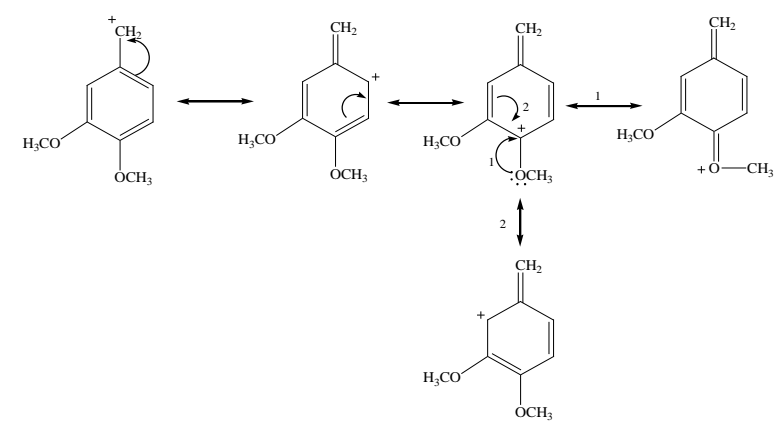

Ion molekul alkohol primer dan sekunder akan mengalami fragmentasi menjadi air dan alkena (Sastrohamidjojo, 1981). Alkohol sekunder dan tersier dapat dengan mudah terlepas substituen terbesar menghasilkan pecahan dengan rumus umum $\mathrm{R}-\mathrm{CH}=\mathrm{OH}$, sedang pada alkohol primer tidak terjadi pemecahan serupa, hal ini dapat digunakan untuk membedakan antara alkohol primer dengan alkohol sekunder dan tersier (Silverstein, 1986). Ion molekul terbentuk bila molekul netral ditumbuk oleh berkas elektron dan melepaskan elektron.
Ion molekul alkohol primer dan sekunder akan mengalami fragmentasi menjadi air dan alkena (Sastrohamidjojo, 1981). Alkohol sekunder dan tersier dapat dengan mudah terlepas substituen terbesar menghasilkan pecahan dengan rumus umum $\mathrm{R}-\mathrm{CH}=\mathrm{OH}$, sedang pada alkohol primer tidak terjadi pemecahan serupa, hal ini dapat digunakan untuk membedakan antara alkohol primer dengan alkohol sekunder dan tersier (Silverstein, 1986). Ion molekul terbentuk bila molekul netral ditumbuk oleh berkas elektron dan melepaskan elektron. Puncak ion molekul alkohol dengan $\mathrm{m} / \mathrm{z}=196$ dapat mengalami fragmentasi seperti di atas. Berdasarkan hasil analisis produk yang telah dilakukan dapat disimpulkan bahwa hasil hidroborasi-oksidasi metileugenol adalah senyawa 3-(3,4-dimetoksi fenil)-1-propanol sebanyak 15,30 g dengan rendemen mencapai $81,29 \%$.

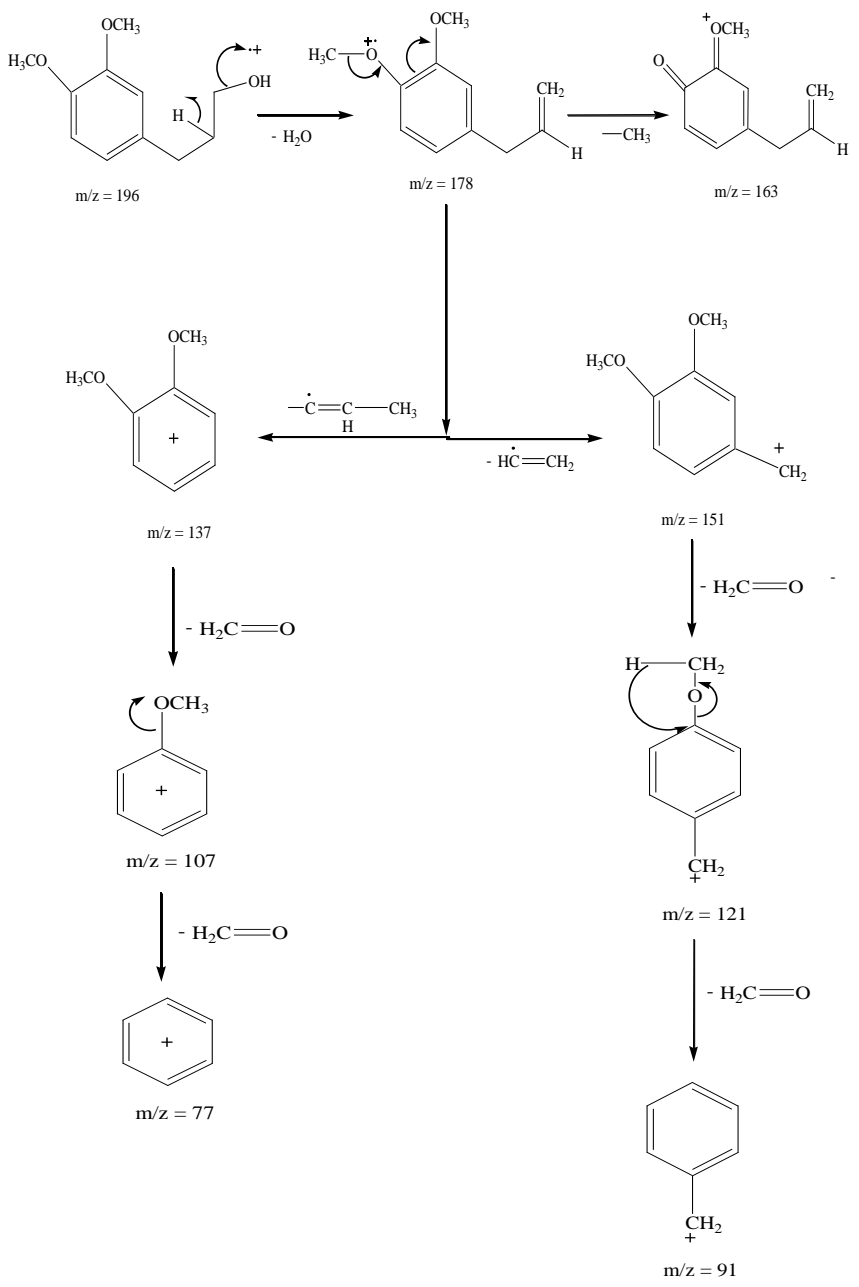




\section{KESIMPULAN}

Berdasarkan dari hasil penelitian dan pembahasan dapat disimpulkan sebagai berikut:

1. Senyawa 3-(3,4-dimetoksi fenil)-1-propanol dapat disintesis melalui metileugenol menggunakan reagen $\mathrm{H}_{3} \mathrm{~B}$ :dietileter selain $\mathrm{H}_{3} \mathrm{~B}$ :THF yang biasa digunakan.

2. Hasil reaksi hidroborasi metileugenol yang diperoleh memiliki rendemen mencapai $81,29 \%$

\section{DAFTAR PUSTAKA}

Anderson, R., 1991, "Sample and Separation", 134-136, Biddles Ltd, Great Britain.

Anwar, C., 1994, "The Conversi of Eugenolin to more Valuable Substances", Desertasi, Matematics and Natural Sciences Faculty, Gadjah Mada University: Yogyakarta.

Carey, F., 2003, "Organic Chemistry; Chapter 6: Reactions of Alkenes: Addition Reactions", $1^{\text {st }}$ ed., Carlottesville, Virginia Universirty.

Creswell, R., Runguist, D.A., and Chamber, M.M., 1982, "Analisis Spektrum Senyawa Organik", ITB: Bandung.

Fessenden J.R., dan Fessenden J. S., 1990, "Kimia Organik", Jilid 2, Edisi ketiga, Erlangga: Jakarta.

Fessenden J.R., dan Fessenden J. S., 1997, "Kimia Organik", Jilid I, Edisi keempat, Erlangga: Jakarta.

Hart, H., 1991, "Organic Chemistry", $8^{\text {th }}$ ed., Houghton Mifflin Company, Michigan State University.

Huang, S. W., Wei-Li Peng, Zi-Xing Shan and De-Jie Zhao, 2001, "A new facile approach to highly selective hydroboration of alkenes with sodium malonyloxyborohydride", Department of Chemistry, Wuhan University, P. R. China.

Jumina, Siswanta D., dan Zulkarnain AK., 2001, "Pemanfaatan Lignin dari Limbah Industri Kertas dan Serbuk Gergaji untuk Pembuatan Turunan Antibiotik C-9154", Jurusan Kimia, Universitas Gadjah Mada: Yogyakarta.

Khopkar, S.M., 1990, "Konsep Dasar Kimia Analitik", 128-131, Penerbit Universitas Indonesia: Jakarta.
Louis,F., and Kenneth, L., "Organic Experiment", $6^{\text {th }}$ edition, Heath anad Company: Massachusets.

Sastrohamidjojo, H., 1981, "A Study of Some Indonesian Essentials Oils", Disertasi, 100114, Universitas Gadjah Mada.

Siadi, K., 2001, "Sintesis 2-Amino-4-(3,4dimetoksi fenil)-butana nitril dari metileugenol melalui reaksi hidroborasi oksidasi dan strcker", Tesis Pasca Sarjana, Universitas Gadjah Mada: Yogyakarta.

Silverstein, R. M., Bassler, G. C., dan Morril, T. C., 1986, "Penyidikan Spektrometrik Senyawa Organik", edisi keempat, Erlangga: Jakarta. 